\title{
Performance, metabolic, hemodynamic, and perceived exertion in the six-minute step test at different heights in a healthy population of different age groups
}

\author{
Túlio Medina Dutra de Oliveira $^{1}$ (D), Cristino Carneiro Oliveira ${ }^{1}$ (D), \\ Vanessa Salles Albuquerque $^{1}$ (D), Marissa Rocha $\operatorname{Santos}^{1}$ (D), Diogo Simões Fonseca ${ }^{1}$ (D), \\ Anderson José ${ }^{1}$ (D), Carla Malaguti ${ }^{1}$ \\ ${ }^{1}$ Universidade Federal de Juiz de Fora, Programa de Pós-Graduação em Ciências da \\ Reabilitação, Juiz de Fora, MG, Brasil.
}

Associate Editor: Eduardo Lusa Cadore, Escola Superior de Educação Física, Universidade Federal do Rio Grande do Sul, UFRGS, Porto Alegre, RS, Brasil.

\begin{abstract}
Aim: This study aimed to compare the performance, metabolic, hemodynamic, and perceived exertion during the 6-minute step test (6MST) conducted with different step heights in healthy subjects and also to compare the performance between different age groups for each step height. The association between age, body mass index, level of physical activity, and lower limb measurements with performance were also evaluated. Methods: This is a cross-sectional study. Anthropometric measures, physical performance, and cardiovascular stress were evaluated during a selfpaced 6MST with different step heights in healthy subjects in the age group of 18-59. All the participants underwent three-step tests $(15 \mathrm{~cm}, 20 \mathrm{~cm}$, and $30 \mathrm{~cm})$ on the same day, in a randomized order. Results: Forty participants $(20 \mathrm{men}$ and 20 women) performed the tests. The performance in the test for the highest step was significantly lower compared to the step with the lowest height $(152 \pm 24$ vs. $173 \pm 27$ and $184 \pm 33 ; p<0,05)$. The estimated peak oxygen consumption $\left(\mathrm{VO}_{2 \text { peak }}\right.$ ) increased by $\sim 2.5 \mathrm{~mL} \cdot \mathrm{kg}^{-1} \cdot \mathrm{min}^{-1}$ with the increase in step height. Hemodynamic variables, such as percent of maximum heart rate $\left(\% \mathrm{HR}_{\text {máx }}\right)$, and systolic blood pressure increased as the step height increased. There was a fair correlation between performance and the level of physical activity in the test with a step height of $15 \mathrm{~cm}$ and $20 \mathrm{~cm}$. Conclusion: A higher step height caused greater cardiovascular stress, without exceeding the submaximal levels of the test, indicating that the $6 \mathrm{MST}$ can be used as an accurate instrument for evaluating aerobic capacity in healthy individuals.
\end{abstract}

Keywords exercise test, 6-minute step test, health.

\section{Introduction}

In the rehabilitation process, the exercise capacity can be assessed by maximum or submaximal tests in both healthy individuals and clinical populations. The cardiopulmonary exercise test is considered as the gold standard for assessing the exercise capacity in clinical practice ${ }^{1}$; however, its use is limited due to the expensive equipment and specialized staff ${ }^{2}$. On the other hand, functional tests, also called "field tests", are valid, reliable, less complex, low cost, and easy to use.

The six-minute walk test and the six-minute step test (6MST) are widely known among the field tests and are associated with disease prognosis, estimating oxygen consumption, and identifying functional limitations, response to interventions, and oxygen desaturation on exertion ${ }^{3,4}$. Although the six-minute walk test is the most used ${ }^{5}$, it requires large spaces (i.e., a corridor that is at least $30 \mathrm{~m}$ long) that are free of obstacles, limiting its application both in in-home or hospital settings ${ }^{6}$. Conversely, the 6MST maintains the benefits of field tests and does not require large physical spaces ${ }^{7}$.

Despite the original step test protocols that were developed to evaluate athletes and healthy individuals, its use has now been validated in older adults and different clinical populations, such as those with chronic obstructive pulmonary disease, idiopathic pulmonary fibrosis, cardiovascular diseases, stroke, and patients undergoing bone marrow transplantation ${ }^{8-13}$. The 6MST is described in the literature using protocols that differ by step height, rhythm, and cadence ${ }^{14}$. In clinical populations, the performance in the 6MST has been assessed with free-cadence aiming to represent the functional activities that people do in the normal course [and context] of their lives to meet the basic need, and it is usually performed at a level that does not require nor meet the maximal exercise capacity ${ }^{23}$. 
Specifically, the step height may influence the workload since higher steps require biomechanical adaptations and greater muscular work in individuals of shorter stature. Muscular work, in turn, can influence aerobic demand and performance during the test ${ }^{15,16}$. An understanding of the impact of the step height on the performance of the 6MST is critical to developing valid methods for the evaluation of physical functional status. However, the effect of step height on the performance and physiological and perceptual response during the $6 \mathrm{MST}$ remains unclear.

In this context, the present study aimed to compare the performance (i.e., the total number of steps), perceived exertion, and metabolic and hemodynamic parameters during the 6MST conducted with different step heights in healthy subjects. The performance in each 6MST among different age groups was also compared. Finally, the association between age, body mass index, level of physical activity, and lower limb measurements with performance were evaluated.

\section{Methods}

\section{Study design and ethical aspects}

This is a cross-sectional study that was carried out within the confines of the Declaration of Helsinki and approved by the Research Ethics Committee (number 3.134.323). All individuals signed an informed consent form.

\section{Participants}

Recruitment was performed via the internet, personal invitations, and posters fixed at the university and in the community. Healthy adults, both sexes and the age ranging between 18-59 years old, were included in the study. Those who were pregnant or had a previous diagnosis of heart disease (except for controlled hypertension with no $\beta$-blocker use), a smoking history, uncontrolled metabolic diseases (i.e., diabetes mellitus), orthopedic, neuromuscular, or rheumatic diseases, a body mass index (BMI) $>30 \mathrm{~kg} / \mathrm{m}^{2}$, or limitations to understand the commands during the test were excluded from the study.

\section{Procedures}

The eligible participants were advised not to exercise $48 \mathrm{~h}$ before the visit and also not fast or have heavy meals before the tests. The previous assessment included a clinical evaluation with history-taking and physical examination aimed at determining co-morbidities and certifying the physical and cognitive conditions to perform the tests.

Data were collected by the same experienced researcher previously trained to perform the 6MST. The participants were divided according to the following age groups: $18-28,29-39,40-49$, and 50-59 years. The measurements performed included anthropometry and assess- ment of the physical activity level. The 6MST was performed randomly on the same day on platforms of $15 \mathrm{~cm}, 20 \mathrm{~cm}$, and $30 \mathrm{~cm}$ height (6MST-15, 6MST-20, and 6MST-30, respectively). The randomization order was obtained by simple drawing.

\section{Measures}

The lower limb length was obtained using a segmometer (Cescorf®, Porto Alegre, Brazil) by measuring the distance between the greater trochanter and the medial malleolus ${ }^{17}$. A measuring tape was used to measure the waist, thigh, and calf circumferences ${ }^{17}$. A stadiometer was used to measure the height (in centimeters), while the weight was assessed using a digital scale $\left(\right.$ Welmy ${ }^{\circledR}$, São Paulo, Brazil). From the BMI value, the participants were classified as underweight, normal weight, overweight, obesity class I, obesity class II, and obesity class III $^{18}$.

The physical activity level was assessed using the short version of the International Physical Activity Questionnaire (IPAQ), a valid and reliable assessment tool among Brazilian individuals ${ }^{19,20}$. This questionnaire consists of seven questions that estimate the time spent on different physical activity levels per week and physical inactivity, including domestic chores, leisure, and sports. After answering the questionnaire, the participants were classified as: very active, active, irregularly active, and sedentary ${ }^{19}$.

Six-minute step test

The 6MST was performed in an isolated room to avoid possible noise and external stimuli that would interfere with the participant's performance. Platforms of $15 \mathrm{~cm}, 20 \mathrm{~cm}$, and $30 \mathrm{~cm}$ high, $40 \mathrm{~cm}$ wide, $60 \mathrm{~cm}$ long, that had non-slip rubber flooring and handless were used. Support for the upper limb was not available. Although the speed of the test was not controlled (i.e., self-paced), the participants were instructed to climb up and down the maximum number of steps for six minutes with the lower limb that felt more comfortable, being also able to alternate the limb with which they started the climb ${ }^{21,22}$. Free cadence (self-paced) was allowed because 6MST intends to represent functional activities, that is, tasks performed in daily life, which are usually performed at a level chosen by the individual and does not require or reach the maximum exercise capacity ${ }^{5,23}$.

Every minute, the participants received standardized verbal incentives based on the principles for the six-minute walking test (e.g., "you are doing well, keep going") using the same tone of voice for each sentence ${ }^{5}$. The heart rate (HR) and oxygen saturation were recorded at rest, immediately, and one and two minutes after the test, using a pulse oximeter (DellaMed®, Caxias do Sul, Brazil) ${ }^{24}$. The percentage of maximum heart rate $\left(\% \mathrm{HR}_{\text {máx }}\right)$ was defined as $220 \mathrm{bpm}$-age. The modified Borg scale ${ }^{25}$ was used to assess the perceived level of dyspnea and leg 
effort, which ranges from zero ("nothing at all") to ten ("very, very strong"). Blood pressure was measured at rest and immediately after the test with an aneroid sphygmomanometer (Premium $®$, Rio de Janeiro, Brazil). One test was performed in each step $(15 \mathrm{~cm}, 20 \mathrm{~cm}$, and $30 \mathrm{~cm}$ height) with a twenty-minute interval in between, or until the baseline variables (HR and perceived exertion) returned to resting levels. Additionally, the horizontal and vertical mechanical works (W) were calculated using the following equations, respectively: $\mathrm{W}_{\text {horizontal }}=0.35 \mathrm{x}$ steps $\cdot \mathrm{min}^{-1}$ and $\mathrm{W}_{\text {vertical }}=(2.4 \mathrm{x}$ steps $/ \mathrm{min}) \mathrm{x}_{\text {height }}$ step $(\mathrm{m})^{26}$. The sum of these two works $\left(\mathrm{W}_{\text {horizontal }}+\mathrm{W}_{\text {vertical }}\right)$ provided an estimate of the peak oxygen consumption $\left(\mathrm{VO}_{2 \text { peak }}\right)$, including $\mathrm{VO}_{2}$ spent at rest ${ }^{26}$. A complete movement was defined as the succession of a step up and down of each lower limb. The timer was not stopped during the test, and the total number of climbed steps was recorded.

\section{Statistical analysis}

Normality and data distribution was verified using the Shapiro-Wilk test. Numeric variables are shown as mean \pm standard deviation (SD). Ordinary one-way analysis of variance with a Tukey post-hoc test was used to compare the 6MST variables (test performance, HR behavior, blood pressure, effort perception, and the estimated $\mathrm{VO}_{2 \text { peak }}$ ) with different platform heights. Ordinary twoway analysis of variance with Tukey post-hoc was used to compare the performance between the 6MST with different platform heights and age groups. Relationships between performance with age and anthropometric measures were assessed using Pearson's or Spearman's correlation coefficient and the relationships between performance and physical activity level were assessed using Kendall's tau-b correlation analysis. Inferential analysis was performed using SPSS version 22.0 (IBM Corp., USA). The calculation of the sample power and the effect size was performed by $\mathrm{G}^{*}$ Power 3.1, using the performance (main outcome) of three platform heights (mean \pm $\mathrm{SD})$ as a reference to perform the statistical test. The level of statistical significance for all tests was set at $p<0.05$ (two-tailed).

\section{Results}

The sample power was $89 \%$ and the effect size was considered large (Cohen's $f=0,47$ ) considering the outcome performance in the three platform heights. Three people were excluded during screening, two due to BMI > $30 \mathrm{~kg} / \mathrm{m}^{2}$ and one who was diagnosed with Crohn's disease. Four older people (age $>60$ years old) were also excluded. Forty participants completed the study. No adverse events were recorded during the tests. The main characteristics of the sample are shown in Table 1.
Table 1 - Characteristics of the participants. $(n=40)$.

\begin{tabular}{lc}
\hline Variable & Values \\
\hline Age (years) & $38.2 \pm 12.5$ \\
Male/female & $20 / 20$ \\
BMI $\left(\mathrm{kg} \cdot \mathrm{m}^{-2}\right)$ & $24.5 \pm 2.7$ \\
Waist circumference $(\mathrm{cm})$ & $85.1 \pm 8.5$ \\
Thigh circumference $(\mathrm{cm})$ & $50.5 \pm 4.2$ \\
Calf circumference $(\mathrm{cm})$ & $37.7 \pm 3.9$ \\
RLLL (cm) & $88.6 \pm 4.7$ \\
IPAQ & \\
$\quad$ Very active & $19(47.5)$ \\
$\quad$ Active & $14(35)$ \\
$\quad$ Irregularly active A & $6(15)$ \\
$\quad$ Irregularly active B & $1(2.5)$ \\
$\quad$ Sedentary & $0(0)$ \\
\hline
\end{tabular}

Data are presented as mean \pm standard deviation and $\mathrm{n}(\%)$.

RLLL: right lower limb length / BMI: body mass index / IPAQ: International Physical Activity Questionnaire.

Table 2 shows the performance and behavior of the monitored variables during 6MST-15, 6MST-20, and 6MST-30. The total number of steps was significantly lower with the increasing step height $(\mathrm{p}<0,05)$. The heart rate change $(\Delta \mathrm{HR})$ (i.e., the difference between values at the end of the 6MST and basal HR), dyspnea, $\mathrm{W}_{\text {vertical, }}$, $\mathrm{W}_{\text {horizontal, }}$ and $\mathrm{VO}_{2 \text { peak }}$ (mL.kg-1.min-1) also increased according to the step height. $\mathrm{HR}_{\text {final }}, \% \mathrm{HR}_{\max }, \mathrm{HR}_{\mathrm{rec} 1}$,

Table 2 - Comparison of physical, cardiovascular, and symptom performance between tests $(n=40)$.

\begin{tabular}{|c|c|c|c|}
\hline & 6MST-15 & 6MST-20 & 6MST-30 \\
\hline Total number of steps & $184.7 \pm 33.1$ & $173.8 \pm 27.6$ & $152.8 \pm 24.3^{* \dagger}$ \\
\hline $\mathrm{HR}_{\text {final }}$ & $119.9 \pm 20$ & $125.6 \pm 18.4$ & $134.9 \pm 21.5^{*}$ \\
\hline$\% \mathrm{HR}_{\max }$ & $0.65 \pm 0.10$ & $0.69 \pm 0.11$ & $0.74 \pm 0.11^{*}$ \\
\hline$\Delta \mathrm{HR}$ & $37.7 \pm 15.3$ & $44.7 \pm 15.4$ & $57.3 \pm 17.7^{* \dagger}$ \\
\hline $\mathrm{HR}_{\text {recl }}$, & $96 \pm 17.4$ & $99.3 \pm 15.1$ & $105.1 \pm 17.3^{*}$ \\
\hline $\mathrm{HR}_{\mathrm{rec} 2}$ & $89.1 \pm 14.7$ & $90.7 \pm 13.6$ & $95.1 \pm 16.8$ \\
\hline $\mathrm{SBP}_{\text {final }}$ & $133.4 \pm 17.6$ & $139.4 \pm 15.8$ & $149 \pm 21.5^{*}$ \\
\hline $\mathrm{DBP}_{\text {final }}$ & $72.6 \pm 11.8$ & $70.2 \pm 11.3$ & $64.7 \pm 12.4^{*}$ \\
\hline Borg dyspnea & $3.0(0-9.0)$ & $3.0(0-8.0)$ & $5.0(1-9.0)^{* \dagger}$ \\
\hline Borg fatigue & $3.0(0-9.0)$ & $4.0(0-8.0)$ & $4.0(0-8.0)^{*}$ \\
\hline $\mathrm{W}_{\text {vertical }}$ & $10.9 \pm 2$ & $13.8 \pm 2.2 *$ & $18.2 \pm 2.9^{*} \dagger$ \\
\hline $\mathrm{W}_{\text {horizontal }}$ & $10.7 \pm 1.9$ & $10 \pm 1.6$ & $8.8 \pm 1.4 * \dagger$ \\
\hline $\mathrm{VO}_{2 \text { peak(mL.kg-1.min-1) }}$ & $21.6 \pm 3.9$ & $23.8 \pm 3.8$ & $27.1 \pm 4.3 * \dagger$ \\
\hline
\end{tabular}

Data are presented as mean \pm SD or median and intervals according to data normality.

$(* \dagger p<0,05) *$ for significant differences compared with 6MST-15. $\dagger$ for significant differences compared with 6MST-20.

Abbreviations: HR: heart rate / $\triangle \mathrm{HR}$ : difference between final and basal HR / SBP: systolic blood pressure / DBP: diastolic blood pressure / rec1': recovery in the first minute / rec2': recovery in the second minute / 6MST-15: 15-cm step test / 6MST-20: 20-cm step test / 6MST-30: 30-cm step test $/ \mathrm{VO}_{2 \text { peak }}$ : peak oxygen consumption / W: work. 
systolic blood pressure, and diastolic blood pressure at the end of the test $\left(\mathrm{SBP}_{\text {final }}\right.$ and $\left.\mathrm{DBP}_{\text {final }}\right)$, and the subjective feeling of leg effort were significantly higher in 6MST-30 compared with 6MST-15. No differences were observed in the diastolic blood pressure (DBP) and HR in between the 1 st and 2 nd minutes of the tests.

Table 3 shows the total number of steps performed for each age subgroups. Although without significant differences, a decrease in performance can be observed with increasing age.

Table 4 shows the correlations between performance in each test and the age, BMI, lower limb length, waist circumference, thigh circumference, calf circumference, and physical activity level. Relationships were observed between the performance in the two tests (6MST-15 and 6MST-20) and physical activity level. The performance in 6MST-15 was correlated with the calf circumference.

Figure 1 shows the estimated marginal mean data for performance in different step heights by age subgroups. Although there was no significant difference, it is possible to observe that, especially from the age of 40 , the test performance decreases regardless of the step height and falls more sharply after the age of 50 .

Table 3 - The total number of climbed steps between age groups $(n=40)$.

\begin{tabular}{ccccc}
\hline & $\mathbf{1 8 - 2 8}$ years & $\mathbf{2 9 - 3 9}$ years & $\mathbf{4 0 - 4 9}$ years & 50-59 years \\
\hline & $\mathrm{n}=10$ & $\mathrm{n}=10$ & $\mathrm{n}=10$ & $\mathrm{n}=10$ \\
6MST-15 & $198 \pm 35$ & $185 \pm 37.1$ & $183.8 \pm 17.4$ & $172 \pm 38.2$ \\
6MST-20 & $172.1 \pm 27.6$ & $174.2 \pm 27.7$ & $179.7 \pm 23.5$ & $169.5 \pm 34$ \\
6MST-30 & $156.2 \pm 23.9$ & $160.1 \pm 25.1$ & $154.1 \pm 19.4$ & $141.1 \pm 27.7$
\end{tabular}

Data are presented as mean \pm SD.

Abbreviations: 6MST-15: 15-cm step test / 6MST-20: 20-cm step test / 6MST-30: 30-cm step test.

$(* \mathrm{p}<0,05)$.

Table 4 - Correlations between sample characteristics and cardiovascular performance $(n=40)$.

\begin{tabular}{lccc}
\hline $\mathbf{n = 4 4}$ & $\mathbf{6 M S T - 1 5}$ & $\mathbf{6 M S T - 2 0}$ & $\mathbf{6 M S T - 3 0}$ \\
\hline Age & -0.25 & -0.43 & -0.22 \\
BMI & -0.27 & -0.18 & -0.24 \\
IPAQ total score & $0.36^{*}$ & $0.25^{*}$ & 0.19 \\
RLLL & 0.28 & 0.11 & 0.06 \\
Waist circumference $(\mathrm{cm})$ & 0.12 & 0.32 & -0.24 \\
Thigh circumference $(\mathrm{cm})$ & 0.12 & 0.32 & -0.25 \\
Calf circumference $(\mathrm{cm})$ & $-0.32^{*}$ & -0.23 & -0.29
\end{tabular}

Data are presented as Pearson's $r$ correlation coefficient for continuous variables ( $\mathrm{r}: \leq 0,25$ : little or no relationship / $\mathrm{r}: 0,25-0,5$ : fair / r: 0,5-0,75: moderate / $r \geq 0,75$ : strong relationship) and Kendall's tau-b coefficient for categorical variables

$(* \mathrm{p}<0.05)$.

Abbreviations: BMI: body mass index / IPAQ: International Physical Activity Questionnaire / RLLL: right lower limb length / 6MST-15: 15cm step test / 6MST-20: 20-cm step test / 6MST-30: 30-cm step test.

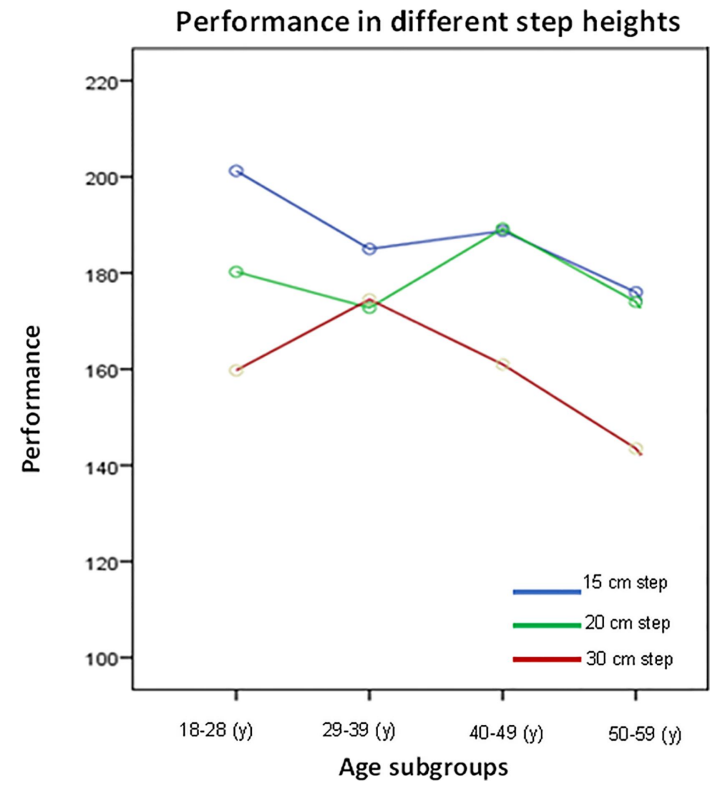

Figure 1 - Estimated marginal mean data for performance in different step heights by age subgroups $(n=40)$. Performance: number of steps climbed in 6MST / y: years / cm: centimeters.

\section{Discussion}

This is the first study investigating physical performance, hemodynamic variables, and mechanical work in healthy individuals during the 6MST performed at different heights and in a self-paced manner. The results indicate that the total number of climbed steps decreases with the increase in step height. Higher steps also influence the estimated $\mathrm{VO}_{2 \text { peak }}, \Delta \mathrm{HR}$, dyspnea, leg effort, and mechanical work. Lastly, the number of climbed steps was associated with the BMI and physical activity level, independent of the platform height used.

The influence of instruments with larger dimensions on functional capacity was also evaluated in other clinical tests. Nakamura et al. ${ }^{27}$ investigated the effects of different seat heights on the incremental sit-to-stand test in healthy women and observed a lower performance and an increase of peak $\mathrm{VO}_{2}$ with the decreasing seat height. This can be explained by the increase in joint load and lower limb muscle activity, which work against the greater influence of the force of gravity. The increase in the maximum movement generated by the knee joint and the floor reaction force would become greater when rising from a lower seat $^{27}$. The test performance decreases proportionately with increased cardiovascular stress and energy expenditure, especially in individuals with lower aerobic fitness levels ${ }^{28}$. This corroborates with the inverse relationship between step height and the total number of climbed steps observed in our study. Possibly, climbing a high step would also cause an increase in the reaction force on the platform, and consequently, a greater maximum movement generated by the hip and knee joints. 
Similarly, the step height increase led to an increase in $\mathrm{VO}_{2 \text { peak }}$, probably due to greater fiber recruitment of both the lower limb and trunk muscles. The use of a greater amount of muscle mass may be the reason for the greater cardiovascular stress and the $\mathrm{VO}_{2 \text { peak }}$ differences observed between tests ${ }^{29}$. Several studies used the step test with different heights $(15 \mathrm{~cm}, 20 \mathrm{~cm}$, and $30 \mathrm{~cm})$ to assess $\mathrm{VO}_{2 \text { peak }}$ in different populations ${ }^{30-32}$, and the highest $\mathrm{VO}_{2 \text { peak }}$ values were found in those tests performed with higher platform heights and fixed cadence. The novel finding of this study is that higher $\mathrm{VO}_{2 \text { peak }}$ values are also achieved when the test is performed in a self-paced manner. Karsten and Lima ${ }^{33}$ reinforced that the free cadence allows the patient to adjust the rhythm according to his/her limitations, thus avoiding an early test interruption.

The results of our study indicate that the higher the step height, the higher the $\Delta \mathrm{HR}$. Besides, a higher \%HR was observed using the $30 \mathrm{~cm}$ step (220 bpm - age). "Beutner et al. ${ }^{32}$ observed that a 3-minute step test with a $30 \mathrm{~cm}$ step and fixed cadence was appropriate to estimate aerobic capacity in healthy individuals ( $\geq 9$ METs)." However, $33 \%$ of the older adults and $15 \%$ of the total sample ( $\leq 9$ METs) did not complete the test, and most participants exceeded submaximal levels, with cardiovascular responses $>80 \%$ of predicted $\mathrm{HR}_{\max }$. In our study, the $30 \mathrm{~cm}$ step led to greater cardiovascular stress and, consequently, higher HR values. Although the test was conducted in six minutes and required a maximum number of steps, the free cadence allowed the individuals to manage their performance at each instant and not exceed the submaximal levels, which is the rationale of the test for the clinical assessment of functional capacity.

The $\mathrm{W}_{\text {vertical }}$ increased with the step height, while the $\mathrm{W}_{\text {horizontal }}$ decreased. This is explained by the fact that the former considers the step height in its equation, while the latter considers only the total number of climbed steps. The sum of the work in both directions provides the aerobic capacity estimation during the $6 \mathrm{MST}^{34,26}$. Culpepper and Francis ${ }^{16}$ proposed equations for healthy men and women taking into account both the individuals' height and hip flexion angle to estimate the ideal step height; with this, the energy expenditure resulting from biomechanical inefficiency during the test is reduced, and the test is standardized for each individual. Webb et al. ${ }^{35}$ used the same equation with individualized step heights and concluded that the four-minute test performed in fixed cadence provided an accurate estimate of the aerobic capacity in healthy individuals. In our study, an average step height value of 32 centimeters was obtained from the aforementioned equation. The findings of the present study support the use of individualized heights since greater cardiovascular stress (i.e., increased $\mathrm{VO}_{2 \text { peak }}, \%$ $\mathrm{HR}_{\max }$, and final SBP) was achieved in the 6MST using the $30 \mathrm{~cm}$ step height. Nevertheless, no association between the physical performance in the 6MST per- formed with different step platform heights and the lower limb length was observed.

Pitta et al. ${ }^{36}$ observed a relationship between the daily physical activity level, measured by an accelerometer, and the six-minute walk test performance, both in chronic respiratory patients and healthy individuals. In this same perspective, Oppert et al. ${ }^{37}$ observed an association between the physical activity level and the 8-minute step test performance in healthy women. This fact was observed in the present study in which the physical activity level was related to the $6 \mathrm{MST}$ performance in the tests with a step height of $15 \mathrm{~cm}$ and $20 \mathrm{~cm}$, indicating that the 6 MST may reflect the level of functional exercise to perform daily physical activities using these step heights.

The relationship observed between the performance on the 6MST-15 at the $15 \mathrm{~cm}$ step height and the calf circumference can be explained by the low step height to favor most of the aerobic activities associated with the predominant composition of type I fibers in the calf muscles, which are $57 \%$ present in the gastrocnemius and $85 \%$ in the soleus ${ }^{38}$ and more resistant to fatigue ${ }^{39}$. On the other hand, the tests with higher steps can produce greater vertical mechanical work by raising the body's own weight against gravity at greater heights, requiring more strength and anaerobic demand with more recruitment of type II fibers.

The present study had some limitations. First, by stratifying the sample into age groups, the sample size for each group reduced, which may have caused a reduction in the statistical power and, consequently, type II error. Second, the sample size was not previously estimated, however, the statistical power was 0.89 and the effect size was considered large (Cohen's $f=0.47$ ). Third, the small height variation of the participants precluded a more precise correlation between the lower limb length and the total number of climbed steps in the test. Fourth, $\mathrm{VO}_{2 \text { peak }}$ was measured indirectly using a predictive equation rather than a gas analyzer, which is considered the gold standard. Fifth, the sample was predominantly active according to the IPAQ, thus the results cannot be extrapolated to a population of less active individuals. Lastly, the individuals were not familiar with the 6MST procedures and this factor may have influenced the results.

\section{Conclusion}

The step height influences the 6MST performance, cardiovascular responses, symptoms, and mechanical work of healthy individuals. The physical activity level was correlated with the physical performance during the 6MST using $15 \mathrm{~cm}$ and $20 \mathrm{~cm}$ step heights. The number of climbed steps was associated with the calf circumference in the $15 \mathrm{~cm}$ step height. 


\section{Acknowledgments}

The authors acknowledge the financial support given by the Coordenação de Aperfeiçoamento de Pessoal de Nível Superior - Brasil (CAPES) - Finance Code 001.

\section{References}

1. Wassermann K, Beaver WL, Whipp BJ. Mechanisms and patterns of blood lactate increase during exercise in man. Med Sci Sports Exerc. 1986;18(3):344-52.

2. Goto K, Ishii N, Sugihara S, Yoshioka T, Takamatsu K. Effects of resistance exercise on lipolysis during subsequent submaximal exercise. Med Sci Sports Exerc. 2007;39 (2):308-15.

3. Travensolo C, Goessler K, Porton R, Pinto RR, Polito DM. Medida do desempenho físico por testes de campo em programas de reabilitacão cardiovascular: revisão sistemática e meta-análise. Rev Port de Cardiol. 2018;37(6):525-37.

4. Sartor F, Vernillo G, Moree H. Estimation of maximal oxygen uptake via submaximal exercise testing in sports, clinical, and home settings. Sports Med. 2013;43(9):865-73.

5. Crapo RO, Casaburi R, Coates AL, Enright PL, McIntyre NR, McKay RT, et al. ATS statement: Guidelines for the six-minute walk test. Am J Respir Crit Care Med. 2002;166 (1):111-7.

6. Annegarn J, Meijer K, Passos VL, Stute K, Weichert J, Savelberg $\mathrm{HH}$, et al. Problematic activities of daily life are weakly associated with clinical characteristics in COPD. J Am Med Dir Assoc. 2012;13(3):284-90

7. Marrara TK, Marino MD, Jamami M, Junior ODA, Di Lorenzo PAV. Responsividade do teste do degrau de seis minutos a um programa de treinamento físico em pacientes com DPOC. J Bras Pneumol. 2012;38(5):579-87.

8. Pessoa VB, Arcuri FJ, Labadessa GI, Costa FNJ, Sentanin CA, Di Lorenzo PAV. Validity of the six-minute step test of free cadence in patients with chronic obstructive pulmonary disease. Braz J Phys Ther. 2014;18(3):228-36.

9. Chehere B, Bougault V, Gicquello A, Wallaert B. Cardiorespiratory response to different exercise tests in interstitial lung disease. Med Sci Sports Exerc. 2016;48(12):2345-52.

10. Giacomantonio N, Morrison P, Rasmussen R, MackayLyons JM. Reliability and validity of the 6-minute step test for clinical assessment of cardiorespiratory fitness in people at risk of cardiovascular disease. J Strength Cond Res. 2018;34(5):1376-82.

11. Da Silva DT, Raimundo DR, Ferreira C, Pasin TC, Monteiro $\mathrm{MBC}$, Junior TAO. Comparison between the six-minute walk test and the six-minute step test in post-stroke patients. Int Arch Med. 2013;6:31.

12. Fioritto AP, Oliveira CC, Albuquerque VS, Almeida LB, Granger CL, Denehy L, et al. Individualized in-hospital exercise training program for people undergoing hematopoietic stem cell transplantation: a feasibility study. Disabil Rehabil. 2019;11;1-7.

13. Neder JR, Nery LE. Fisiologia clínica do exercício. São Paulo, Artes Médicas, 2003.

14. Andrade CHS, Camargo, AA, Castro BP, Malaguti C, Dal Corso C. Comparison of cardiopulmonary responses during
2 incremental step tests in subjects with COPD. Respir Care. 2012;57(11):1920-6.

15. Bennet H, Parfitt G, Davison K, Eston R. Validity of submaximal step tests to estimate maximal oxygen uptake in healthy adults. Sports Med. 2016;46(5):737-50.

16. Culpepper MI, Francis KT. An anatomical model to determine step height in step testing for estimating aerobic capacity. J Theor Biol. 1987;129(1):1-8.

17. Stewart A, Marfell-Jones M. International Standards for Anthropometric Assessment. 3 ed. New Zealand, International Society for the Advancement of Kinanthropometry, 2011.

18. WHO. Obesity: Preventing and managing the global epidemic. WHO technical report series. WHO, Geneva, Switzerland, 2000.

19. Matsudo S, Araujo T, Matsudo V, Andrade D, Andrade E, Oliveira LC, et al. Questionário internacional de atividade física (IPAQ): estudo de validade e reprodutibilidade no Brasil. Rev Bras Ativ Fís Saúde. 2001;6(2):5-18.

20. Craig CL, Marshal AL, Sjostrom M, Bauman AE, Booth ML, Ainsworth B, et al. International physical activity questionnaire: 12-country reliability and validity. Med Sci Sports Exerc. 2003;35(8):1381-95.

21. Dal Corso S, Duarte SR, Neder JA, Malaguti C, Fuccio MB, Castro CAP. A step test to assess exercise-related oxygen desaturation in interstitial lung disease. Eur Respir J. 2007;29(2):330-6.

22. Arcuri JF, Borghi-Silva A, Labadessa IG, Sentanin AC, Candolo C, Di Lorenzo VAP. Validity and Reliability of the 6-Minute Step Test in Healthy Individuals. Clin J Sport Med. 2016;26(1):69-75.

23. Bui KL, Nyberg A, Maltais F, Saey D. Functional Tests in Chronic Obstructive Pulmonary Disease, Part 1: Clinical Relevance and Links to the International Classification of Functioning, Disability, and Health. Ann Am Thorac Soc. 2017;14(5):778-84. doi: 10.1513/AnnalsATS.201609733AS. PMID: 28244799.

24. Cole CR, Blackstone EH, Pashkow FJ, Snader CE, Lauer MS. Heart-rate recovery immediately after exercise as a predictor of mortality. N Engl J Med. 1999;341(18):1351-7.

25. Borg GA. Psychophysical bases of perceived exertion. Med Sci Sports Exerc. 1982;14(5):377-81.

26. Kaminsky LA, Pescatello LS, Arena R, Riebe D, Thompson PD. ACSM's Guidelines for Exercise Testing and Prescription. 4 ed. Philadelphia: Lea \& Febiger, 1997.

27. Nakamura K, Nagasawa Y, Sawaki S, Yokokawa Y, Ohira $M$. Effect of different seat heights during an incremental sitto-stand exercise test on peak oxygen uptake in young, healthy women. J Sports Sci Med. 2016;15(3): 410-16.

28. Nyberg LA, Hellenius M, Wandell P, Kowalski J, Sundberg J. Maximal step-up height as a simple and relevant health indicator: a study of leg muscle strength and the associations to age, anthropometric variables, aerobic fitness, and physical function. Br J Sports Med. 2013;47(15):992-7.

29. Hill DW, Vingren JL. Effects of exercise mode and participant sex on measures of anaerobic capacity. J Sports Med Phys Fitness. 2014;54(3):255-63.

30. Carvalho LP, Luporini LT, Leheudre MA, Junior JB, Oliveira CR, Luporini RL. Prediction of cardiorespiratory fitness by the six-minute step test and its association with 
muscle strength and power in sedentary obese and lean young women: a cross-sectional study. PloS One. 2015;10 (12).

31. Knight E, Stuckey M, Petrella R. Validation of the step test and exercise prescription tool for adults. Can J Diabetes. 2014;38(3):164-71.

32. Beutner F, Ubrich R, Zachariae S, Engel C, Sandri M, Teren A, et al. Validation of a brief step-test protocol for estimation of peak oxygen uptake. Eur J Prev Cardiol. 2015;22 (4):503-12.

33. Karsten M, Lima WC. Análise da cadência utilizada por idosos independentes funcionalmente durante o teste do banco com cadência livre. Braz J Phys Ther. 2006;10:82-3.

34. Bohannon WR, Bubela JD, Wang CY, Magasi SS, Gershon CR. Six-minute Walk Test versus Three-minute Step Test for Measuring Functional Endurance (Alternative Measures of Functional Endurance). J Strength Cond Res. 2015;29 (11): 3240-44.

35. Webb C, Vehrs PR, George JD, Hager R. Estimating $\mathrm{VO}_{2}$ max Using a Personalized Step Test. Meas Phys Educ Exerc Sci. 2014;18(3):184-97.

36. Pitta F, Troosters T, Spruit MA, Probst VS, Decramer M, Gosselink R. Characteristics of physical activities in daily life in chronic obstructive pulmonary disease. Am J Respir Crit Care Med. 2005;171(9):972-7.

37. Oppert JM, Charles MA, Charreire H, Menai M, Bourdeaudhuji I, Brage S, et al. Home and Work Physical Activ- ity Environments: Associations with Cardiorespiratory Fitness and Physical Activity Level in French Women. Int J Environ Res Public Health. 2016;13(8):824.

38. Trappe SW, Trappe TA, Lee GA, Costill DL. Calf muscle strength in humans. Int J Sports Med. 2001;22(3):186-91.

39. Picard M, Hepple RT, Burelle Y. Mitochondrial functional specialization in glycolytic and oxidative muscle fibers: tailoring the organelle for optimal function. Am J Physiol Cell Physiol. 2012;302(4):629-41.

\section{Corresponding author}

Carla Malaguti. Av. Eugênio do Nascimento, s/n - Dom Bosco, 36038-330 Juiz de Fora, MG, Brasil.

E-mail: carlamalaguti@gmail.com.

Manuscript received on October 30, 2020

Manuscript accepted on March 3, 2021

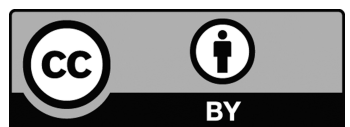

Motriz. The Journal of Physical Education. UNESP. Rio Claro, SP, Brazil - eISSN: 1980-6574 - under a license Creative Commons - Version 4.0 